\title{
Remaining Useful Life Estimation of Wind Turbine Blades under Variable Wind Speed Conditions Using Particle Filters
}

\author{
Bhavana Valeti ${ }^{1}$, and Shamim N Pakzad ${ }^{2}$ \\ ${ }^{1,2}$ Lehigh University, Bethlehem, PA, 18015, USA \\ bhv214@lehigh.edu \\ pakzad@lehigh.edu
}

\begin{abstract}
Rotor blades are the most complex structural components in a wind turbine and are subjected to continuous cyclic loads of wind and self-weight variation. The structural maintenance operations in wind farms are moving towards condition based maintenance (CBM) to avoid premature failures. For this, damage prognosis with remaining useful life (RUL) estimation in wind turbine blades is necessary. Wind speed variation plays an important role influencing the loading and consequently the RUL of the structural components. This study investigates the effect of variable wind speed between the cutin and cut-out speeds of a typical wind farm on the RUL of a damage detected wind turbine blade as opposed to average wind speed assumption. RUL of wind turbine blades are estimated for different initial crack sizes using particle filtering method which forecasts the evolution of fatigue crack addressing the non-linearity and uncertainty in crack propagation. The stresses on a numerically simulated life size onshore wind turbine blade subjected to the above wind speed loading cases are used in computing the crack propagation observation data for particle filters. The effects of variable wind speed on the damage propagation rates and RUL in comparison to those at an average wind speed condition are studied and discussed.
\end{abstract}

\section{INTRODUCTION}

Wind energy has grown to be one of the most popular sources of renewable energies around the world within a span of two decades. The size and capacities of individual wind turbines have rapidly increased over time to meet the clean energy goals and demands (Wymore, Van Dam, Ceylan, \& Qiao, 2015). In addition to initial installation costs, maintenance and operation costs of wind turbines account to approximately $20-25 \%$ of the total levelized cost per kWh (ElThalji \& Jantunen, 2012). Unlike the popular preventive and

\footnotetext{
Bhavana Valeti et al. This is an open-access article distributed under the terms of the Creative Commons Attribution 3.0 United States License, which permits unrestricted use, distribution, and reproduction in any medium, provided the original author and source are credited.
}

corrective maintenance practices, CBM minimizes unnecessary labor and pre-mature replacement costs due to scheduled maintenance practices (preventive) and expensive postfailure repair and replacement costs (corrective) by optimizing the maintenance schedule based on the RUL, repair and replacement costs (Gupta \& Lawsirirat, 2006). RUL is salient for CBM of components that undergo prolonged deterioration under fluctuating loads before failure, which include blades, tower and other mechanical components in a wind turbine.

\subsection{Fatigue Damage in Wind Turbine Blades and Effect of Wind Speed Fluctuations}

Among the structural components of the wind turbines, rotor blades are subjected to the most dynamically varying loads. Blade damage accounts for around $23 \%$ of the total failure events accompanied by significant downtime and replacement costs (Ciang, Lee, \& Bang, 2008; Florian \& Sørensen, 2015). The wind turbine rotor blades consist of load carrying shear webs or hollow beam laminates for flapwise and edgewise moments along the blade and light weight core to resist torsion and buckling. The laminate frame is made of fiber reinforced polymer composite materials and the core is made of foam or balsa wood and the two are typically bonded by adhesives. The core is covered with composite laminates or gel coats for protection (Mcgugan, Pereira, Sørensen, Toftegaard, \& Branner, 2015; Al-Khudairi et al., 2017). Although the modern wind turbine blades are designed to withstand the loads for at least 20 years, there is always a chance for external causes of damage such as from lightening or an inherent flaw in the complex blade structure during blade manufacture (Nielsen \& Sørensen, 2017). Multiple studies have identified few hotspots (Ciang et al., 2008) in the wind turbine blade structure with high probabilities for damage. Fatigue crack at the blade root, maximum chord location, $30 \%$ and $70 \%$ of blade length from root are some of the frequently encountered fatigue crack locations that are reported from experiments and simulation studies (Kong, Kim, Han, \& Sugiyama, 2006; Schulz \& Sundaresan, 2002). Upper spar cap and its flange are also identified as the critical 
locations depending on the pitch angle of the blade (Shokrieh \& Rafiee, 2006). Delamination, debonding and intralaminar failure are some of the damage modes that need attention in these locations (Lading, McGugan, Sendrup, Rheinländer, \& Rusborg, 2002).

Faults in blades if unchecked can grow in size eventually causing a catastrophic damage to the integrity of system (Ciang et al., 2008). Condition monitoring and diagnosis is the fundamental step in the RUL estimation of wind turbine blades. With many advances in structural damage detection and diagnosis (Yao \& Pakzad, 2012; Shahidi et al., 2015; Yao, Pakzad, \& Venkitasubramaniam, 2017; Gulgec, Takáč, \& Pakzad, 2017), SHM system should be capable enough to detect and localize the faults at a minimum required stage of evolution such that sufficient time is available to achieve economic CBM. Numerous SHM strategies (Kirikera, Schulz, \& Sundaresan, 2007; Rumsey \& Paquette, 2008; Furong Zhang, Yongqian Li, Zhi Yang, \& Liping Zhang, 2009; Kim et al., 2014; LeBlanc, Niezrecki, Avitabile, Chen, \& Sherwood, 2013; Yang, Peng, Wei, \& Tian, 2017) for wind turbine blades have been proposed, studied and tested (Dutton et al., 2003; Kirikera et al., 2008; Ou, Dertimanis, \& Chatzi, 2016; Ou, Chatzi, Dertimanis, \& Spiridonakos, 2016).

Being subjected to highly irregular loads caused by a combination of turbulent wind flow, varying direction of gravitational load, centrifugal loads, triggers the fatigue damage progression in the above mentioned hotspots (Al-Khudairi et al., 2017; Yang et al., 2017). Major cyclic loads are induced by gravity result in edgewise bending and wind loads induce flap-wise and edgewise bending in the blades. In addition to the dynamic component of wind loading wind speed fluctuations can expedite the damage regression. The wind speed experienced by the wind turbines typically varies between a cut-in speed $V_{\text {in }}$ of $2 \mathrm{~m} / \mathrm{sec}$ to a cut-out speed $V_{\text {out }}$ of 25 $\mathrm{m} / \mathrm{sec}$ (Hayat, Asif, Ali, Ijaz, \& Mustafa, 2015) beyond which wind turbine operation is halted. Weibull distribution of wind speeds is typically observed as shown in Fig. 1. Wind speeds can vary day to day and it is anticipated in this paper that this can affect the estimation of RUL in comparison with that of the estimated using a mean wind speed.

In this paper a particle filtering based prognostic procedure is applied for RUL estimation of wind turbine blades subjected to fatigue damage for variable wind speed loading using particle filters. The results are compared to the RULs estimated with a constant average wind speed of $12 \mathrm{~m} / \mathrm{sec}$ which is presented in a previous study by the authors (Valeti \& Pakzad, 2018). The following sections discuss the RUL estimation using particle filters followed by its application in RUL estimation for wind turbine blades under fatigue loading. Following this results of the two wind speed loading conditions mentioned before are discussed and compared.

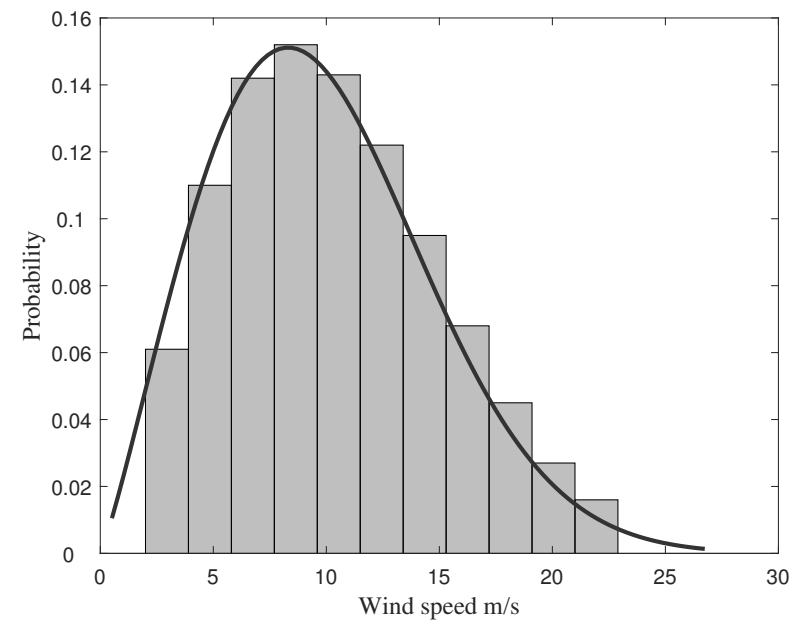

Figure 1. Particle filter algorithm and estimation of RUL

\section{RUL ESTIMATION}

\subsection{Prognosis for RUL Estimation}

RUL of a structural component can be defined as the time between the last known condition to the time when it reaches a predefined threshold condition before maintenance is required (Si, Wang, Hu, \& Zhou, 2011). Prognosis is to predict future behavior which is required for estimation of the RUL of a deteriorating subsystem or a component (Vachtsevanos, Lewis, Roemer, Hess, \& Wu, 2006). Fatigue, being one of the important failure modes in wind turbine blades, the ability to assess RUL considering various uncertainties and current damage state is necessary to make confident and safe maintenance decisions. (Newman, 1981) developed analytical model of cyclic crack growth that includes the effects of crack closure to correlate crack growth under aircraft spectrum loading on aluminum alloy plate material. Several studies have been conducted for determining the RUL in wind turbine blades through classical fatigue crack propagation laws (Shokrieh \& Rafiee, 2006; Beganovic, Njiri, Rothe, \& Soffker, 2015; Hayat et al., 2015). (Corbetta, Sbarufatti, Giglio, Saxena, \& Goebel, 2018) proposed a particle filter based Bayesian damage prognosis framework extended to multiple damage mechanisms for fatigue life prediction of composite laminates under co-existing matrix cracks and delamination. Sanchez et al. (2016) (Sanchez, Sankararaman, Escobet, Frost, \& Goebel, 2016) estimated the RUL for a medium sized wind turbine blade using fatigue stiffness degradation damage model developed for Carbon fiber reinforced polymers (CFRP) materials. The damage model was applied on blade root moment sensor information from a wind turbine simulated in a high fidelity simulator FAST v8 (Fatigue, Aerodynamics, Structures and Turbulence) and subjected to different wind speed scenarios.

(Sikorska, Hodkiewicz, \& Ma, 2011) classified prognostic 
methods specifically for RUL estimation into four categories namely, Knowledge-based models, Life expectancy models (stochastic and statistical), Artificial Neural Networks (ANN) and Physical models. The physical models are the most accurate of the above methods but are expensive with low range of system applicability compared to the knowledge base methods which are on the other end of the spectrum. The ANN's performance on the other hand have been known to be limited to short term prognosis. It is the uncertainties in measured fault, definition of damage characteristics, fault propagation model, material characterization and future loads act as impediments to accurate RUL estimation. Due to these uncertainties, the estimation of confidence limits along with RUL is important. A plethora of literature is available on crack growth modeling and RUL estimation in engineering materials for stochastic deterioration models and statistical data driven approaches through stochastic life expectancy models (Si et al., 2011; Medjaher, Tobon-Mejia, \& Zerhouni, 2012; Le Son, Fouladirad, Barros, Levrat, \& Iung, 2013) without the drawbacks from other methods. The stochastic life expectancy models consider RUL as a statistically identical random variable and define it with a probability density function. This random variable carries the measurement, modeling and loading uncertainties. Dynamic Bayesian network models such as Markov models, Kalman filters and particle filters are some of the stochastic life expectancy models that are popularly used in engineering prognostics (Bartram \& Mahadevan, 2013).

\subsection{RUL Estimation with Particle Filters}

Particle filters are essentially the Monte Carlo based nonlinear Bayesian tracking methods that address the nonlinearity in the state evolution and/or non-Gaussian noise in the process and measurements. Particle filters are particularly useful when the posterior distribution is non-standard or multivariate (Arulampalam, Maskell, Gordon, \& Clapp, 2002; Cadini, Zio, \& Avram, 2009; Zio \& Peloni, 2011). Which makes the method very much suitable for forecasting a nonlinear process such as crack growth (Haile, Riddick, \& Assefa, 2016).

Given a damage propagation process is measured until the current time say $k$, the RUL estimation is performed as described in the following three steps (Fig. 2) (M. Orchard, Wu, \& Vachtsevanos, 2005; An, Choi, \& Kim, 2013). Step 1: Damage state estimation using particle filters upto time $k$, Step 2: p-step ahead prediction $\left(x_{k+1}\right.$ to $\left.x_{k+p}\right)$ until reaching a threshold and Step 3: RUL estimation.

\subsubsection{Step 1: State Estimation}

Nonlinear Bayesian tracking: Define the damage state or crack length $x_{k}$ at time $k$ with a non-linear state transition equation $f_{k}$ as a function of previous damage state at $k-1$ (first order Markov process assumption). Define the mea- sured damage state with observation model $h_{k}$ as a function of the state through the following state space equations Eq. (1) and Eq. (2) (M. Orchard et al., 2005; Cadini et al., 2009; Zio \& Peloni, 2011).

$$
\begin{aligned}
x_{k}=f_{x}\left(x_{k-1}, \omega_{k}\right) & \longleftrightarrow p\left(x_{k} \mid x_{k-1}\right) \\
z_{k}=h_{x}\left(x_{k}, \nu_{k}\right) & \longleftrightarrow p\left(z_{k} \mid x_{k}\right)
\end{aligned}
$$

$\omega_{k}$ and $\nu_{k}$ are non-Gaussian noise vectors of known distributions corresponding to uncertainty in the damage process model and measurements respectively.

Prediction Step: In the prediction step the a priori state is estimated using previous state distribution $p\left(x_{k-1} \mid z_{1: k-1}\right)$ with Chapman-Kolmogorov equation

$$
p\left(x_{k} \mid z_{1: k-1}\right)=\int p\left(x_{k} \mid x_{1: k-1}\right) p\left(x_{k-1} \mid z_{1: k-1}\right) d x_{k-1}
$$

Update Step: The a priori state estimation $p\left(x_{k} \mid z_{1: k-1}\right)$ Eq. (3) is now updated to $p\left(x_{k} \mid z_{1: k}\right)$ with observation $z_{k}$ as shown in Eq. (5) using Bayes rule.

$$
p\left(x_{k} \mid z_{1: k}\right)=\frac{p\left(z_{k} \mid x_{k}\right) p\left(x_{k} \mid z_{1: k-1}\right)}{p\left(z_{k} \mid z_{1: k-1}\right)}
$$

where the normalizing constant

$$
p\left(z_{k} \mid z_{1: k-1}\right)=\int p\left(z_{k} \mid x_{k}\right) p\left(x_{k} \mid z_{1: k-1}\right) d x_{k}
$$

The prediction and update steps are performed recursively for state estimation.

Particle Filters In case of nonlinear processes with nonstandard posterior distributions, particle filters that are approximate nonlinear Bayesian filters that offer sub optimal solution to the Bayesian tracking problem. The key is to use a set of random samples with associated weights to represent the posterior density function. These particles and weights are updated measurement likelihood called sequential importance sampling. Bayesian tracking with a general scheme for particle filters is explained as follows (Jouin, Gouriveau, Hissel, Péra, \& Zerhouni, 2016).

$N_{s}$ particles are created based on a known initial state $x_{o}$ (equivalent to initial crack length). In each iteration the particles for the current state $x_{k \mid k-1}^{i}$ are obtained using Eq. (3), and weights of the particles are updated by Eq. (6) (Arulampalam et al., 2002)

$$
w_{k}=w_{k-1} \frac{p\left(z_{k} \mid x_{k}\right) p\left(x_{k} \mid x_{k-1}\right)}{q\left(x_{k} \mid x_{0: k-1}, z_{1: k}\right)}
$$

where, $q\left(x_{0: k} \mid z_{1: k}\right)$ is importance density function and $p\left(z_{k} \mid x_{k}\right)$ being the likelihood of current state measurement. The posterior state pdf $p\left(x_{k} \mid z_{1: k}\right)$ is approximated by particles with corresponding discrete probability masses (Eq. (7)) with particles and normalized importance weights 


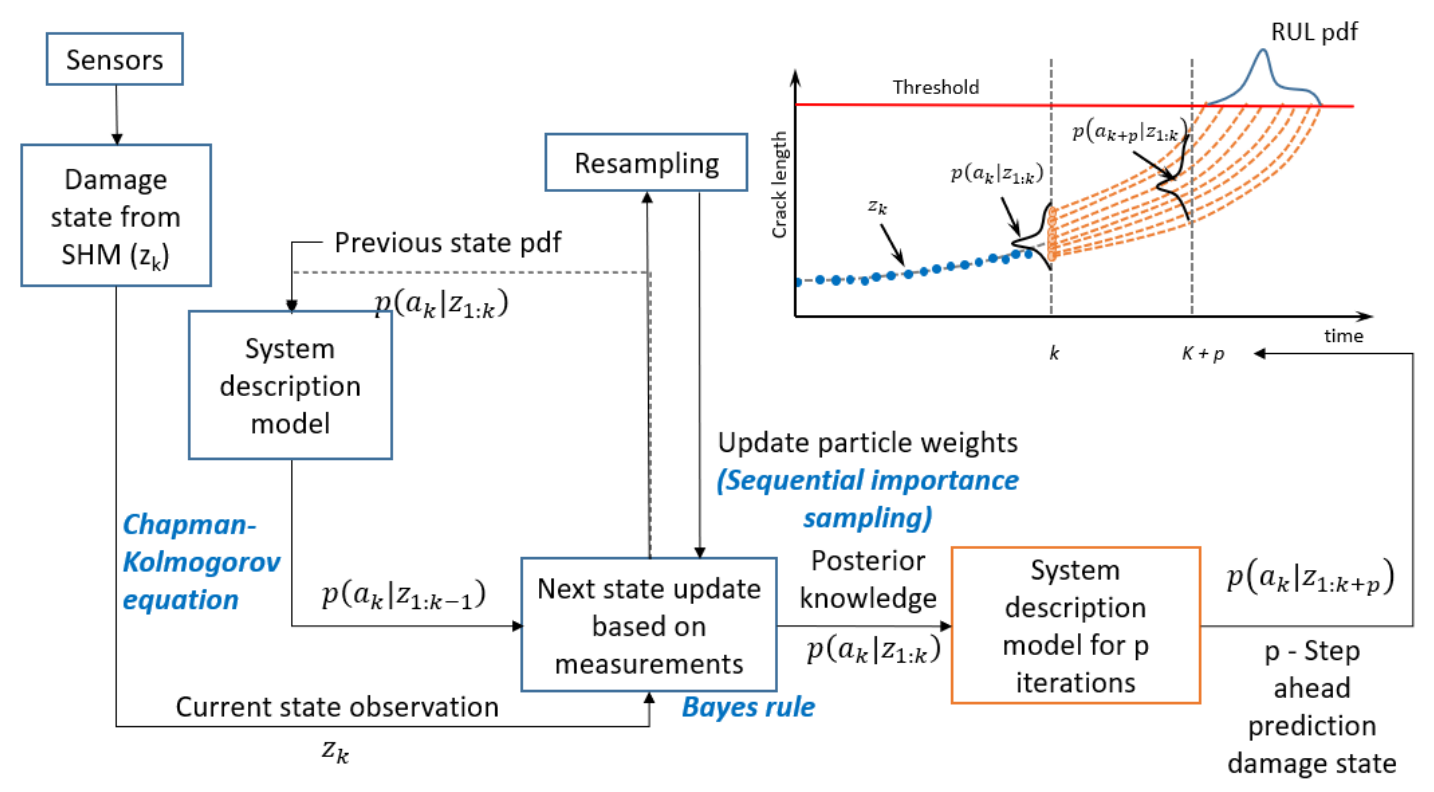

Figure 2. Particle filter algorithm and estimation of RUL

$\tilde{w}_{k}^{i}=\frac{w_{k}^{i}}{\Sigma w_{k}^{i}}$

$$
p\left(x_{k} \mid z_{1: k}\right)=\sum_{i=1}^{N} \tilde{w}_{k}^{i} \delta\left(x_{0: k}-x_{0: k}^{i}\right)
$$

Particle degeneracy is experienced after repeated iterations which increases the variance of $x_{n}$ without bounds as $N \rightarrow$ $\infty$. This eventually results in many particles with zero weights. For a sample size $N_{s}$ degeneracy can be measured from effective sample size $N_{\text {eff }}$ estimated as $\hat{N}_{\text {eff }}=$ $1 / \Sigma_{i=1}^{N_{s}}\left(\omega_{k}^{i}\right)^{2}$. Particles with low weights are eliminated and the other ones duplicated to improve the exploration space at $k+1$ with resampling methods such as inverse transformation method. To avoid unnecessary resampling at every step adaptive resampling can be employed that is to allow resampling only when $\hat{N}_{\text {eff }}<N_{s}$.

\subsubsection{Step 2: Prognosis}

Using the current state estimate and updated fault growth model parameters, long term state predictions are generated by a recursive integration process based on importance sampling Eq. (8) (M. E. Orchard \& Vachtsevanos, 2009).

$$
\begin{array}{r}
p\left(x_{k+p} \mid z_{1: k}\right)=\int p\left(x_{k} \mid z_{0: k}\right) \prod_{j=k+1}^{k+p} p\left(x_{j} \mid x_{k-1}\right) d x_{k: k+p-1} \\
=\sum_{i=1}^{N} w_{k+p-1}^{i} p\left(x_{k+p}^{i} \mid x_{k+p-1}^{i}\right)
\end{array}
$$

Resampling of the particles is performed whenever $\hat{N}_{e f f}<$ $N_{s}$. The weights of resampled particles are kept unchanged every step $\left(\omega_{k+p+1}^{i}=\omega_{k+p}^{i}\right)$. The uncertainty during prognosis is propagated similar manner to the tracking stage.

\subsubsection{Step 3: RUL Estimation}

The residual life of a structure after fatigue crack initiation depends on speed of crack propagation and the of size of critical defect that can be tolerated by the structure under extreme loading (Benedetti, Fontanari, \& Battisti, 2013). RUL is estimated as the weighted average of the duration of time between the end of last observation and when each of the particles reaches the threshold.

$$
p\left(R U L \mid z_{1: k}\right)=\sum_{i=1}^{N} \tilde{w}_{k}^{i} \delta\left(R U L-R U L^{i}\right)
$$

\section{RUL ESTIMATION FOR Wind TURBINE BLADES With Fatigue DaMage}

The effect of variable wind speed in comparison with a constant average wind speed on RUL estimations is studied using a simulated wind turbine blade response. The fatigue damage observations from time to time are generated using the blade response and used in the particle filters based prognosis method discussed above to estimate the RULs. The details of the generation of crack propagation observations, RUL estimation and comparison of the results are elucidated in the following sections. 


\subsection{Generating Fatigue Crack Propagation Observa- tions}

RUL is estimated for a 5MW onshore wind turbine blade with fatigue damage defined by National Renewable Energy Laboratory (NREL) (Jonkman, Butterfield, Musial, \& Scott, 2009; Tezduyar, Sathe, Schwaab, \& Conklin, 2008) simulated in FAST v8 (Jonkma \& Jonkman, 2016) a high fidelity aero-elastic computer aided engineering tool that simulates coupled dynamic responses of horizontal axis wind turbines (Valeti \& Pakzad, 2018). Fatigue crack propagation observations are generated from the stress histories of simulated wind turbine blades under varying and constant wind speed loading (Fig. 3) for initial crack lengths, $a_{o}=0.01$, $0.03,0.05,0.07,0.09$ at $30 \%$ length of the blade $(61.5 \mathrm{~m})$ from root. The stress histories are calculated with dynamic response of the simulated blade subjected to turbulence for a period of $10 \mathrm{~min}$ of a given wind speed. In constant wind speed case $12 \mathrm{~m} / \mathrm{s}$ is used to generate the crack observations representing the average wind speed between $V_{\text {in }}$ and $V_{\text {out }}$ wind speeds typically experienced by onshore wind farms. In case of variable wind speed wind loading histories were generated for wind speeds between $V_{i n}$ and $V_{\text {out }}$. In this study $V_{\text {in }}$ and $V_{\text {out }}$ are chosen as $2 \mathrm{~m} / \mathrm{s}$ and $22 \mathrm{~m} / \mathrm{s}$ respectively. Wind speed loading is changed randomly within this range every $24 \mathrm{hrs}$ to fit a Weibull distribution as shown in Fig. (1). The loads due start and stoppage of wind turbine, sudden gusts are ignored for simplicity and time conservation during simulations. The force response history of the simulated wind turbine blades at multiple locations is stored. This is used to generate axial stress histories using the blade airfoil geometrical properties at desired locations (Jonkman et al., 2009).

Walker's equation for variable loading fatigue crack propagation (Stephens, Fatemi, Stephens, \& Fuchs, 2001) is used to generate crack propagation observations with the blade stress histories (Florian \& Sørensen, 2015). A very strong simplifying assumption is made in this study by modeling delamination and micro-crack density propagation with Walker's equation. Homogeneity of the blade materials is assumed. The change in the stress intensity factor $\Delta K$ with crack growth is calculated from current crack length $a$ and root mean square stress range computed with the Rainflow counting algorithm (Eq. 11) (Downing \& Socie, 1982; Florian \& Sørensen, 2015).

$$
\frac{d a}{d t}=\frac{A(\Delta K)^{m}}{(1-R)^{m\left(1-\lambda_{w}\right)}}
$$

Where,

$$
\begin{gathered}
\Delta K=\sqrt{\frac{\sum_{i=1}^{N} \Delta S_{i}^{2}}{N}} \sqrt{\pi a} \alpha \\
R=\frac{S_{\text {minrms }}}{S_{\text {maxrms }}}
\end{gathered}
$$

Table 1. Model parameters used for generating observations

\begin{tabular}{l|l|l|l}
\hline \hline Parameter & Value (mean) & COV & Distribution \\
\hline \hline$A$ & $1.2^{-9}$ & 0.05 & Normal \\
\hline$m$ & 1.8 & 0.03 & Normal \\
\hline$\lambda_{w}$ & 0.8 & 0.01 & Normal \\
\hline$\alpha$ & 1.0 & - & - \\
\hline$a$ & variable & $1.5 \times 10^{-4}$ & Normal \\
\hline \hline
\end{tabular}

$A, m, \lambda_{w}, \alpha$ are material properties, $R$ is Stress ratio, $S_{\text {minrms }}$ and $S_{\text {maxrms }}$ are the RMS values of minimum and maximum stresses in the stress cycles and $\Delta S$ is the stress range in each stress cycle. Parameter $A$ is represented in a normal distribution (Table 1) equivalent to lognormal distribution fro convenience. The covariance of initial crack length is shown in the table whose mean and covariance vary with evolution of state. The fatigue crack growth observation data is computed with the parameters in Table 1 at $30 \%$ length of the blade from blade root.

For brevity the results for $a_{o}=0.03 \mathrm{~m}$ are discussed in the following sections. Observations generated for $a_{o}=0.03 \mathrm{~m}$ are shown in Fig. 4. For both variable and constant wind speed cases. Change in crack propagation rate is observed with change in the wind speed every 24 hours, in the variable wind speed based observation.

\subsection{Prognosis with Particle Filters}

\subsubsection{RUL Estimation}

Particle filters use the generated observations, transition (Eq. 13) and measurement (Eq. 14) models to generate posterior distributions at the end of chosen number of observations (50 or 100) for different loading conditions discussed above. The uncertainty in the fatigue crack propagation process $\omega_{k}$ is represented by the statistical distribution of parameters as seen in Table 1. Where as the measurement noise at time $k$ is $\nu_{k}$ incorporated as shown in equation as an additive Gaussian noise $\left(\nu_{k} \sim \mathcal{N}\left(0, a_{k} / 0.0001\right)\right.$. Each particle in estimated posterior distribution at the end of the observations $(t=k)$ is projected using the state transition model until their future states reach a predefined threshold $(t=k+p)$. In this case $0.2 m$ is chosen as a reasonable threshold crack length.

$$
\begin{gathered}
a_{k}=\frac{A(\Delta K)^{m}}{(1-R)^{m\left(1-\lambda_{w}\right)}} d t+a_{k-1} \\
z_{k}=a_{k}+\nu_{k}
\end{gathered}
$$

Prognosis for $a_{o}=0.03 \mathrm{~m}$ is shown in Fig. 5 under a constant average wind speed of $12 \mathrm{~m} / \mathrm{s}$ with and particle filtering performed with 50 observations. The filter estimates, prognosis and the observations are shown in the figure. The two gray lines in the plot indicate 5 and 95 percentile of the particles. 


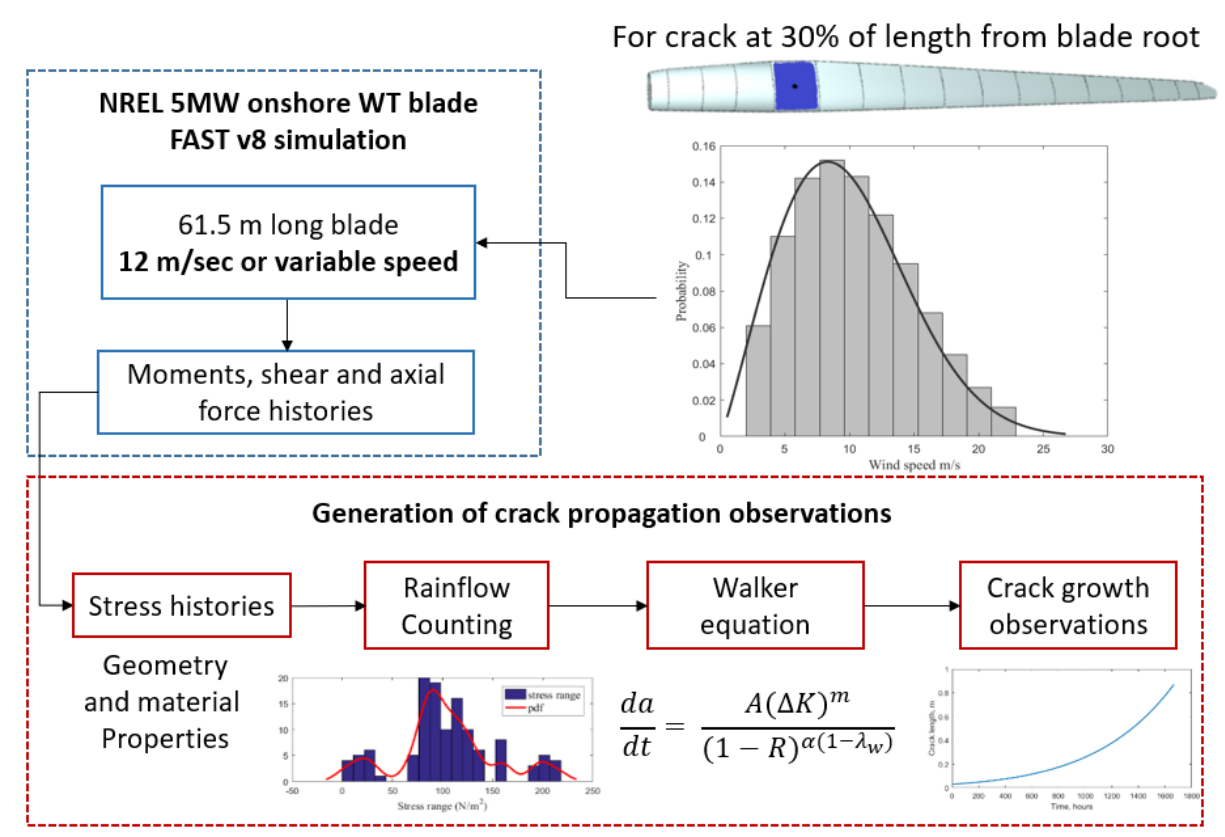

Figure 3. Procedure to generate fatigue crack growth observation data in wind turbine blade

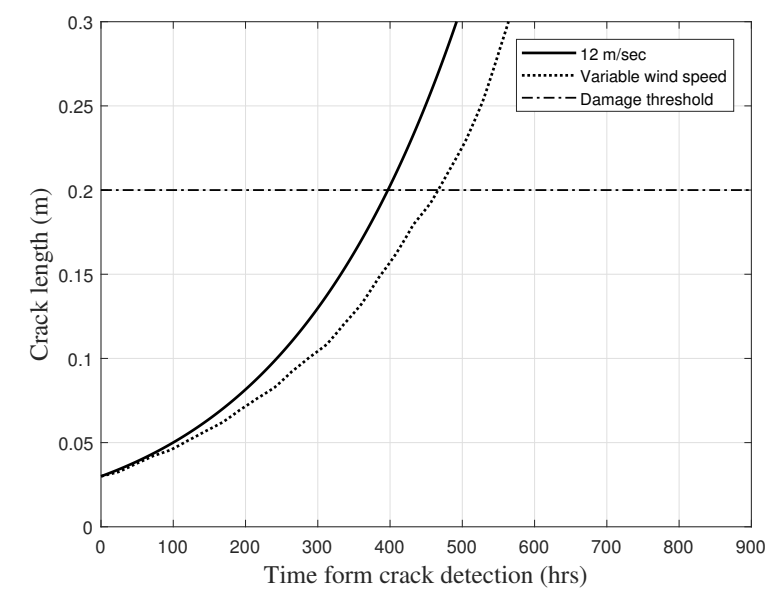

Figure 4. Fatigue crack growth observations generated for $0.03 \mathrm{~m}$ initial crack length under constant and variable loading conditions

We can also notice that individual particles cross the threshold at different times. The distribution of the RUL calculated for each of the particles is shown in a histogram (Fig. 6).

Prognosis for variable wind speed loading for $a_{o}=0.03 \mathrm{~m}$ is shown in Fig. 7 and the corresponding RUL distribution is shown in Fig. 8. We can notice a change in curvature of the estimate and 5 and 95 percentile (PI) particle limits every 24 hrs due to change in the wind speed which is also identified in the observations.

As the RUL distributions of the particles in both wind loading

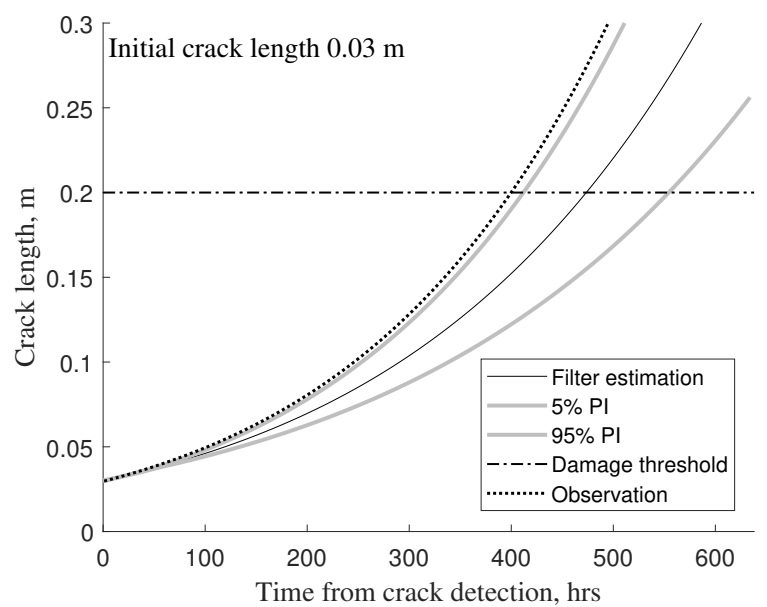

Figure 5. Prognosis for $a_{o}$ of $0.03 m$ with 50 observations under a constant wind speed of $12 \mathrm{~m} / \mathrm{s}$.

cases are observed to be non standard, a weighted average of particle RULs is used for blade RUL estimation. RULs for different $a_{o}$ are shown in Table 2 for both 50 and 100 observations used in the particle filters. One can observe that the RUL estimations for higher $a_{o}$ values are lower. This is anticipated because, the higher $a_{o}$, the closer it is to the threshold and requires less number of load cycles to reach it. Which results in smaller RUL. We can also observe from Table 2 that higher number of observations used in the particle filters resulted in RUL estimated closer to the expected RUL from the simulated observations. This is intuitive because the transi- 


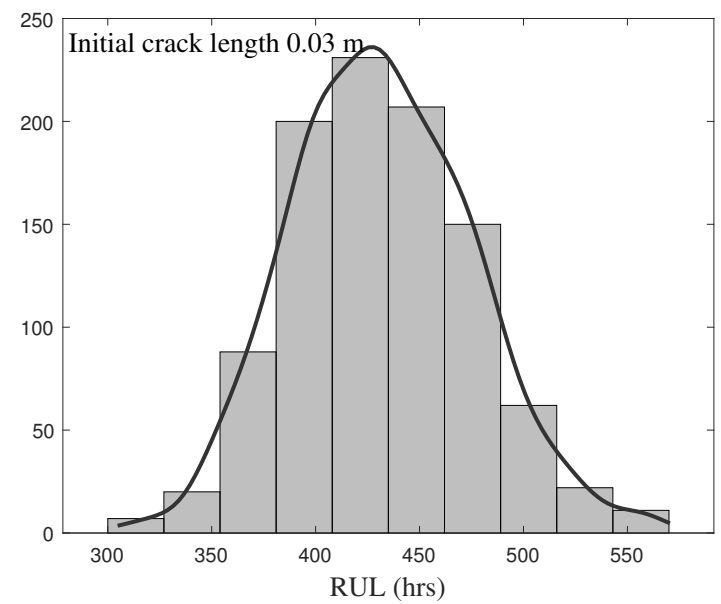

Figure 6. RUL for $a_{o}$ of $0.03 m$ with 50 observations under a constant wind speed of $12 \mathrm{~m} / \mathrm{s}$.

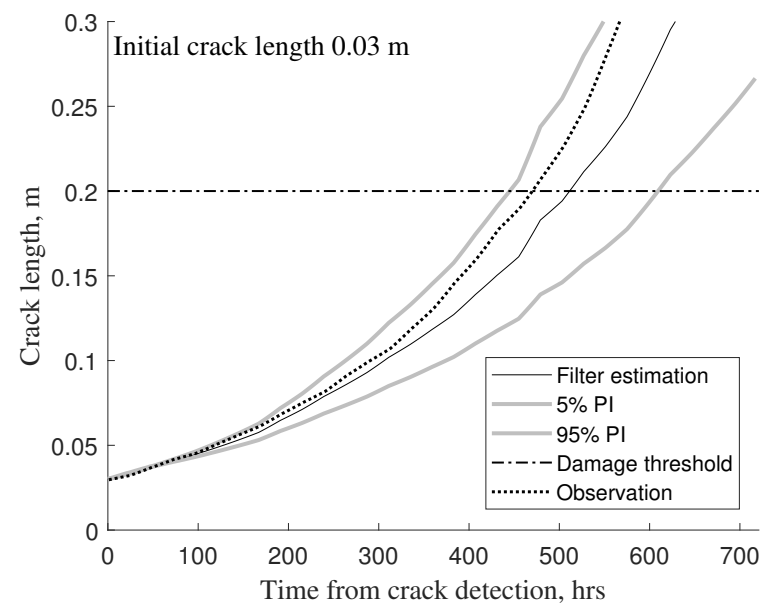

Figure 7. Prognosis for $a_{o}$ of $0.03 m$ with 50 observations under variable wind speed between $2 \mathrm{~m} / \mathrm{s}$ and $22 \mathrm{~m} / \mathrm{s}$.

tion model with latest update (higher number of observations) results in damage estimate closer to actual value.

\subsubsection{RUL Estimate Comparison}

To understand the effect of variable wind speed on the damage progression, the RUL estimates from Table 2 are compared for $12 \mathrm{~m} / \mathrm{sec}$ and variable wind speed cases for $50 \mathrm{ob}-$ servations (Fig. 9) and 100 observations (Fig. 10). The constant average wind speed underestimates the RULs compared to the variable wind speed cases. The lower RUL estimates in case of constant average wind speed loading case is attributed to the faster damage progression in the observations for this case compared to variable wind speed loading. The difference between the RUL estimates seems to decrease with $a_{o}$ closer to the critical crack length or threshold for 50 observations case. This can be justified by the fact that damage progression

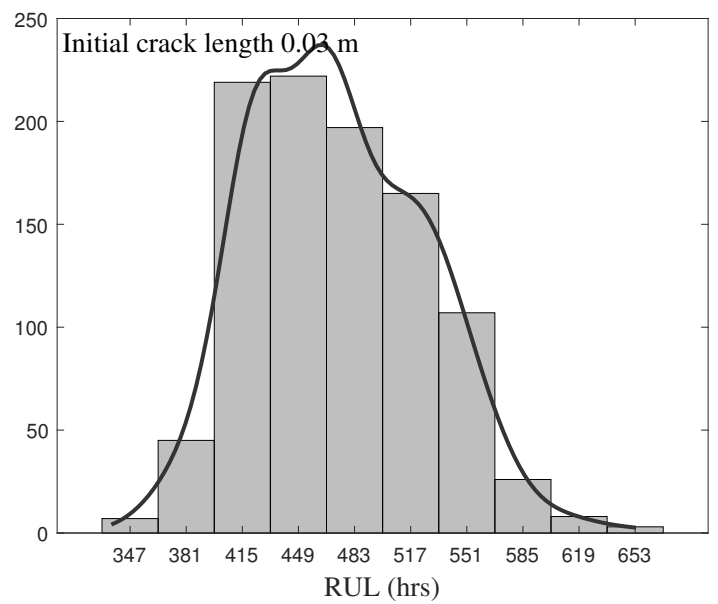

Figure 8. RUL for $a_{o}$ of $0.03 m$ with 50 observations under variable wind speed between $2 \mathrm{~m} / \mathrm{s}$ and $22 \mathrm{~m} / \mathrm{s}$.

rate is high closer to the threshold and the compared loading conditions do not result in much difference. The difference of RULs for both the wind speed loading cases is within a range of 70 to $40 \mathrm{hrs}$ which is 2 to 3 days in the maintenance schedule of wind farm.

\section{Conclusions}

Particle filters were used to estimate the RUL of wind turbine blades with different lengths of initial cracks at 30\% length from blade root for constant wind speed and variable wind speed loading conditions and compared. The following conclusions were drawn as a result of this study:

1. The variable wind speed results in a less conservative estimate of RUL of wind turbine blade in comparison with constant average wind speed of $12 \mathrm{~m} / \mathrm{s}$, in0line with the observations generated for each of the cases. The difference of RULs for both the wind speed loading cases is within a range of 70 to $40 \mathrm{hrs}$ which is 2 to 3 days in the maintenance schedule of wind farm. This should be studied for different average wind speeds depending on the wind speed distribution of a particular farm to generalize the results.

2. The difference between the RUL estimates decreases with $a_{o}$ closer to the critical crack length or threshold

Table 2. RUL Estimations (hrs)

\begin{tabular}{l|l|l|l|l|l|l}
\hline \hline \multirow{2}{*}{$a_{o}(\mathbf{m})$} & \multicolumn{2}{|c|}{ 50 observations } & \multicolumn{2}{c|}{ 100 observations } & \multicolumn{2}{c}{ Observations } \\
\cline { 2 - 7 } & $\mathbf{1 2} \mathbf{~ m} / \mathbf{s}$ & Var & $\mathbf{1 2} \mathbf{~ m} / \mathbf{s}$ & Var & $\mathbf{1 2} \mathbf{~ m / s}$ & Var \\
\hline \hline 0.01 & 666 & 745 & 608 & 677 & 594 & 672 \\
\hline 0.03 & 426 & 476 & 368 & 424 & 397 & 466 \\
\hline 0.05 & 306 & 346 & 248 & 272 & 297 & 352 \\
\hline 0.07 & 221 & 238 & 164 & 216 & 229 & 268 \\
\hline 0.09 & 159 & 171 & 102 & 141 & 176 & 204 \\
\hline \hline
\end{tabular}




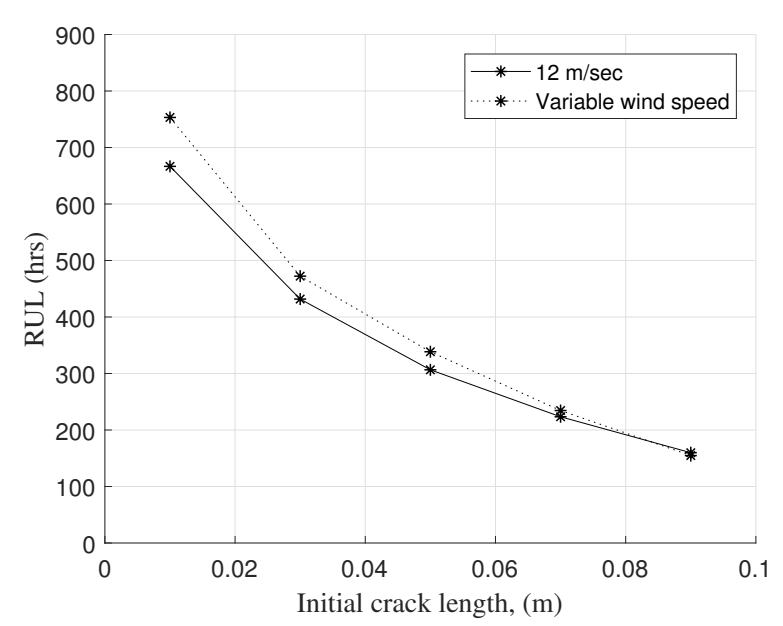

Figure 9. Comparison of RUL of different $a_{o}$ under constant wind speed and variable wind speed with 50 observations

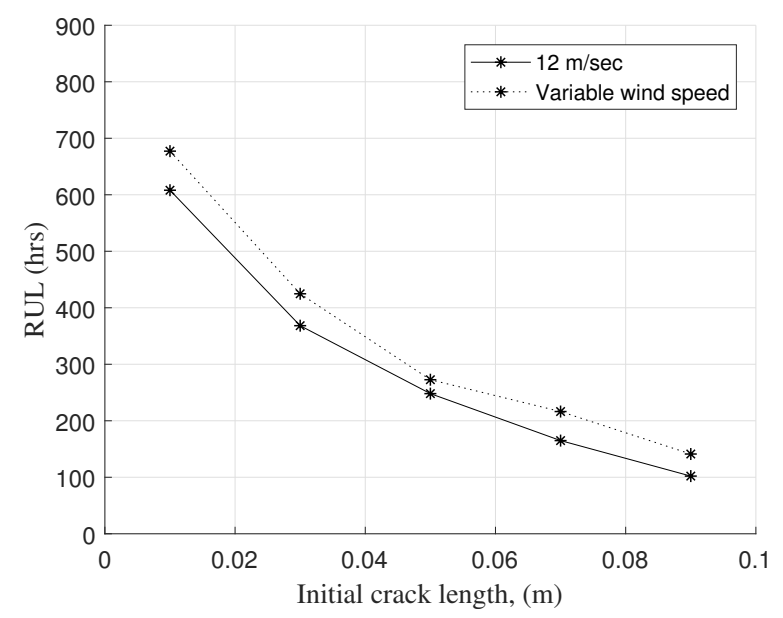

Figure 10. Comparison of RUL of different $a_{o}$ under constant wind speed and variable wind speed with 100 observations

for 50 observations case for different loading conditions. This can be justified by the fact that damage progression rate is high closer to the threshold where the loading conditions chosen for the study did not result in very different RULs.

3. Higher number of observations result in better prognosis and RUL estimation.

4. Particle filters address the nonlinearity in the damage propagation model and the uncertainty in the model parameter definition which makes then very much suitable for prognosis of fatigue damage in wind turbine blades.

\section{ACKNOWLEDGMENT}

Research funding is partially provided by the National Science Foundation through Grant No. CMMI-1351537 by Hazard Mitigation and Structural Engineering program, and by a grant from the Commonwealth of Pennsylvania, Department of Community and Economic Development, through the Pennsylvania Infrastructure Technology Alliance (PITA).

\section{REFERENCES}

Al-Khudairi, O., Hadavinia, H., Little, C., Gillmore, G., Greaves, P., \& Dyer, K. (2017). Full-Scale Fatigue Testing of a Wind Turbine Blade in Flapwise Direction and Examining the Effect of Crack Propagation on the Blade Performance. Materials, 10(10), 1152.

An, D., Choi, J. H., \& Kim, N. H. (2013). Prognostics 101: A tutorial for particle filter-based prognostics algorithm using Matlab. Reliability Engineering and System Safety, 115, 161-169.

Arulampalam, M. S., Maskell, S., Gordon, N., \& Clapp, T. (2002). A tutorial on particle filters for online nonlinear/non-GaussianBayesian tracking. Signal Processing, IEEE Transactions on, 50(2), 174-188.

Bartram, G., \& Mahadevan, S. (2013). Dynamic Bayesian networks for prognosis. In Phm 2013 - proceedings of the annual conference of the prognostics and health management society 2013 (pp. 167-184).

Beganovic, N., Njiri, J. G., Rothe, S., \& Soffker, D. (2015, jun). Application of diagnosis and prognosis to wind turbine system based on fatigue load. In 2015 ieee conference on prognostics and health management (phm) (pp. 1-6). IEEE.

Benedetti, M., Fontanari, V., \& Battisti, L. (2013). Structural health monitoring of wind towers: residual fatigue life estimation. Smart Materials and Structures, 22(4), 045017.

Cadini, F., Zio, E., \& Avram, D. (2009, jul). Monte Carlobased filtering for fatigue crack growth estimation. Probabilistic Engineering Mechanics, 24(3), 367-373.

Ciang, C. C., Lee, J.-R., \& Bang, H.-J. (2008). Structural health monitoring for a wind turbine system: a review of damage detection methods. Measurement Science and Technology, 19(12), 122001.

Corbetta, M., Sbarufatti, C., Giglio, M., Saxena, A., \& Goebel, K. (2018). A bayesian framework for fatigue life prediction of composite laminates under coexisting matrix cracks and delamination. Composite Structures, 187, 58-70.

Downing, S. D., \& Socie, D. F. (1982, jan). Simple rainflow counting algorithms. International Journal of Fatigue, 4(1), 31-40.

Dutton, A., Blanch, M., Vionis, P., Lekou, D., van Delft, D., Joosse, P., ... others (2003). Acoustic emission condition monitoring of wind turbine rotor blades: laboratory certification testing to large scale in-service deployment. In European wind energy conference-ewec.

El-Thalji, I., \& Jantunen, E. (2012). On the development of condition based maintenance strategy for offshore 
wind farm: Requirement elicitation process. In Energy procedia (Vol. 24, pp. 328-339).

Florian, M., \& Sørensen, J. (2015). Wind Turbine Blade Life-Time Assessment Model for Preventive Planning of Operation and Maintenance. Journal of Marine Science and Engineering, 3(3), 1027-1040.

Furong Zhang, Yongqian Li, Zhi Yang, \& Liping Zhang. (2009). Investigation of wind turbine blade monitoring based on optical fiber Brillouin sensor. In 2009 international conference on sustainable power generation and supply (pp. 1-4).

Gulgec, N. S., Takáč, M., \& Pakzad, S. N. (2017). Structural damage detection using convolutional neural networks. In R. Barthorpe, R. Platz, I. Lopez, B. Moaveni, \& C. Papadimitriou (Eds.), Model validation and uncertainty quantification, volume 3 (pp. 331-337). Cham: Springer International Publishing.

Gupta, A., \& Lawsirirat, C. (2006). Strategically optimum maintenance of monitoring-enabled multicomponent systems using continuous-time jump deterioration models. Journal of Quality in Maintenance Engineering, 12(3), 306-329.

Haile, M. A., Riddick, J. C., \& Assefa, A. H. (2016). Robust Particle Filters for Fatigue Crack Growth Estimation in Rotorcraft Structures. IEEE Transactions on Reliability, 65(3), 1438-1448.

Hayat, K., Asif, M., Ali, H. T., Ijaz, H., \& Mustafa, G. (2015). Fatigue life estimation of large-scale composite wind turbine blades. In Applied sciences and technology ( $\mathrm{ib}$ cast), 2015 12th international bhurban conference on (pp. 60-66).

Jonkma, J., \& Jonkman, B. (2016). FAST, National Renewable Energy Laboratory. National Renewable Ennergy Limited.

Jonkman, J., Butterfield, S., Musial, W., \& Scott, G. (2009). Definition of a 5-MW Reference Wind Turbine for Offshore System Development (Tech. Rep.). Golden, Colorado, USA: National Renewable Energy Limited.

Jouin, M., Gouriveau, R., Hissel, D., Péra, M.-C., \& Zerhouni, N. (2016). Particle filter-based prognostics: Review, discussion and perspectives. Mechanical Systems and Signal Processing, 72, 2-31.

Kim, S., Adams, D. E., Sohn, H., Rodriguez-Rivera, G., Myrent, N., Bond, R., ... Meyer, J. J. (2014). Crack detection technique for operating wind turbine blades using Vibro-Acoustic Modulation. Structural Health Monitoring, 13(6), 660-670.

Kirikera, G. R., Schulz, M. J., \& Sundaresan, M. J. (2007). Multiple damage identification on a wind turbine blade using a structural neural system. Sensor Systems and Networks: Phenomena, Technology, and Applications for NDE and Health Monitoring 2007, 6530(2007), T5300.

Kirikera, G. R., Shinde, V., Schulz, M. J., Sundaresan, M. J.,
Hughes, S., van Dam, J., ... Ghoshal, A. (2008, jun). Monitoring Multi-Site Damage Growth During QuasiStatic Testing of a Wind Turbine Blade using a Structural Neural System. Structural Health Monitoring: An International Journal, 7(2), 157-173.

Kong, C., Kim, T., Han, D., \& Sugiyama, Y. (2006, oct). Investigation of fatigue life for a medium scale composite wind turbine blade. International Journal of Fatigue, 28(10), 1382-1388.

Lading, L., McGugan, M., Sendrup, P., Rheinländer, J., \& Rusborg, J. (2002). Fundamentals for Remote Structural Health Monitoring of Wind Turbine Blades a Preproject Annex B Sensors and Non-Destructive Testing Methods for Damage Detection in Wind Turbine Blades Fundamentals for Remote Structural Health Monitoring of Wind Turbi (Tech. Rep.). Risoe-R, Denmark: Forskningscenter Risoe.

Le Son, K., Fouladirad, M., Barros, A., Levrat, E., \& Iung, B. (2013). Remaining useful life estimation based on stochastic deterioration models: A comparative study. Reliability Engineering \& System Safety, 112, 165175.

LeBlanc, B., Niezrecki, C., Avitabile, P., Chen, J., \& Sherwood, J. (2013). Damage detection and full surface characterization of a wind turbine blade using three-dimensional digital image correlation. Structural Health Monitoring, 12, 430-439.

Mcgugan, M., Pereira, G., Sørensen, B. F., Toftegaard, H., \& Branner, K. (2015). Damage tolerance and structural monitoring for wind turbine blades. Philosophical Trans. R. Soc. A, 373(2035).

Medjaher, K., Tobon-Mejia, D. A., \& Zerhouni, N. (2012, jun). Remaining Useful Life Estimation of Critical Components With Application to Bearings. IEEE Transactions on Reliability, 61(2), 292-302.

Newman, J. (1981). A crack-closure model for predicting fatigue crack growth under aircraft spectrum loading. In Methods and models for predicting fatigue crack growth under random loading. ASTM International.

Nielsen, J. S., \& Sørensen, J. D. (2017). Bayesian Estimation of Remaining Useful Life for Wind Turbine Blades. Energies, 10(5), 664.

Orchard, M., Wu, B., \& Vachtsevanos, G. (2005). A Particle filtering frmaework for failure prognosis. In World tribology congress iii, volume 2 (pp. 1-2). Washington D.C., USA.

Orchard, M. E., \& Vachtsevanos, G. J. (2009). A particlefiltering approach for on-line fault diagnosis and failure prognosis. Transactions of the Institute of Measurement and Control, 31(3-4), 221-246.

Ou, Y., Chatzi, E. N., Dertimanis, V. K., \& Spiridonakos, M. D. (2016). Vibration-based experimental damage detection of a small-scale wind turbine blade. Structural Health Monitoring, 16(1), 79-96. 
Ou, Y., Dertimanis, V. K., \& Chatzi, E. N. (2016). Experimental damage detection of a wind turbine blade under varying operational conditions. In Proceedings of isma (pp. 4183-4198).

Rumsey, M. A., \& Paquette, J. A. (2008). Structural health monitoring of wind turbine blades. In Smart sensor phenomena, technology, networks, and systems (p. 15). SIPE.

Sanchez, H., Sankararaman, S., Escobet, T., Frost, S., \& Goebel, K. (2016). Analysis of two modeling approaches for fatigue estimation and remaining useful life predictions of wind turbine blades. In European conference of the prognostics and health management society (pp. 1-11).

Schulz, M. J., \& Sundaresan, M. J. (2002). Smart Sensor System for Structural Condition Monitoring of Wind Turbines: May 30, 2002 - April 30, 2006, Subcontract Report NREL/SR-500-40089 (Tech. Rep.). National Renewable Energy Laboratory.

Shahidi, S. G., Yao, R., Chamberlain, M. B. W., Nigro, M. B., Thorsen, A., \& Pakzad, S. N. (2015). Datadriven Structural Damage Identification Using DIT. In Imac33 (pp. 2-9).

Shokrieh, M. M., \& Rafiee, R. (2006). Simulation of fatigue failure in a full composite wind turbine blade. Composite Structures, 74(3), 332-342.

Si, X. S., Wang, W., Hu, C. H., \& Zhou, D. H. (2011). Remaining useful life estimation - A review on the statistical data driven approaches. European Journal of Operational Research, 213(1), 1-14.

Sikorska, J., Hodkiewicz, M., \& Ma, L. (2011). Prognostic modelling options for remaining useful life estimation by industry. Mechanical Systems and Signal Processing, 25(5), 1803-1836.

Stephens, R. I., Fatemi, A., Stephens, R. R., \& Fuchs, H. o. (2001). Metal Fatigue in Engineering (2nd ed.).

Tezduyar, T. E., Sathe, S., Schwaab, M., \& Conklin, B. S. (2008). Arterial fluid mechanics modeling with the stabilized space time fluid structure interaction technique. International Journal for Numerical Methods in Fluids(October 2007), 601-629.

Vachtsevanos, G., Lewis, F. L., Roemer, M. ., Hess, A., \& Wu, B. (2006). Intelligent Fault Diagnosis and Prognosis for Engineering Systems.

Valeti, B., \& Pakzad, S. N. (2018). Estimation of remaining useful life of a fatigue damaged wind turbine blade with particle filters. In C. Juan \& S. Pakzad (Eds.), Dynamics of civil structures, volume 2 (p. 266-290). Springer.

Wymore, M. L., Van Dam, J. E., Ceylan, H., \& Qiao, D. (2015). A survey of health monitoring systems for wind turbines. Renewable and Sustainable Energy Reviews, 52(1069283), 976-990.

Yang, W., Peng, Z., Wei, K., \& Tian, W. (2017). Structural health monitoring of composite wind turbine blades: challenges, issues and potential solutions. IET Renewable Power Generation, 11(4), 411-416.

Yao, R., \& Pakzad, S. N. (2012, aug). Auto-regressive statistical pattern recognition algorithms for damage detection in civil structures. Mechanical Systems and Signal Processing, 31, 355-368.

Yao, R., Pakzad, S. N., \& Venkitasubramaniam, P. (2017). Compressive sensing based structural damage detection and localization using theoretical and metaheuristic statistics. Structural Control and Health Monitoring, 24(4).

Zio, E., \& Peloni, G. (2011, mar). Particle filtering prognostic estimation of the remaining useful life of nonlinear components. Reliability Engineering \& System Safety, 96(3), 403-409.

\section{BIOGRAPHIES}

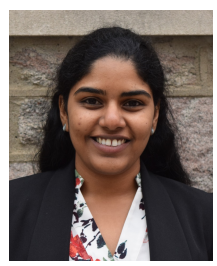

Bhavana Valeti was born in Vijayawada, India in 1990. She graduated with B.E., Civil Engineering from Andhra University, India in 2011. She graduated with Master of Technology in Structural Engineering from Indian Institute of Technology, Kanpur, India in 2013. She is currently pursuing P.HD. in structural Engineering at Lehigh University. She worked on a variety of topics in structural Engineering including, Earthquake Engineering, Fluid and Soil structure interaction, Fatigue and fracture mechanics. Her Research interests include Structural health monitoring, Damage detection, Signal Procession and Prognostic modeling. She is currently working on structural health monitoring and maintenance of onshore wind farms. She is a member of ASCE, Structural Engineering Institute (SEI) and Society of Experimental Mechanics(SEM).

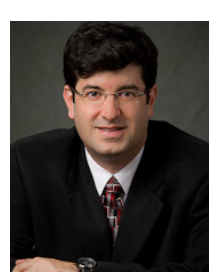

Shamim N Pakzad, Ph.D was born in Iran. He graduated with B.S., Civil Engineering from The Baha'i Institute for Higher Education, Iran, Tehran, 1995. He graduated with M. S., Civil and Environmental Engineering from San Jose State University, San Jose, California in 2000 and with Ph.D., Civil and Environmental Engineering from The University of California, Berkeley in 2008 , followed by a postdoctoral Appointment in Structural Engineering at the The University of California, Berkeley in 2008. He is at present Associate Professor and Director of CEE Graduate Programs at Lehigh University, USA. His areas of research include structural health monitoring; wireless sensor networks; damage detection; system identification and signal processing; probabilistic methods in civil engineering and structural reliability; random vibrations and structural dynamics; and structural monitoring of large infrastructures and bridges; Disaster Management and Resilience of the Infrastructure. He received the NSF Career award in 2014 for 'Toward a Mobile Sensing Platform for Bridge Condition Monitoring'. He is the chair for Dynamics of Civil Structures technical division for the Society of Experimental Mechanics (SEM). He is a member of ASCE, Structural Engineering Institute (SEI). 